\title{
zmiz1a zebrafish mutants have defective erythropoiesis, altered expression of autophagy genes, and a deficient response to vitamin $D$
}

Francisco Castillo-Castellanos ${ }^{1}$, Laura Ramírez $^{1}$, and Hilda Lomelí ${ }^{1 *}$

${ }^{1}$ Departamento de Genética del Desarrollo y Fisiología Molecular. Instituto de Biotecnología, Universidad Nacional Autónoma de México,

*Corresponding author

hilda@ibt.unam.mx

Key words: erythropoiesis, zebrafish, autophagy, vitamin D response, ZMIZ1 


\section{ABSTRACT}

ZMIZ1 is a transcriptional coactivator that is related to members of the protein inhibitor of activated STAT (PIAS) family. ZMIZ1 regulates the activity of various transcription factors including the androgen receptor, p53, and Smad3. ZMIZ1 also interacts with Notch1 and selectively regulates Notch1 target genes relevant for $\mathrm{T}$ cell development and leukemogenesis in mammals. Human ZMIZ1 is additionally characterized as a latitudedependent autoimmune disease (LDAD) risk gene, as it is responsive to vitamin $\mathrm{D}$ and has been associated with at least eleven blood cell traits.

To address the function of ZMIZ1 in fish, we introduced CRISPR/Cas9 mutations in the zmizla gene in zebrafish. We observed that inactivation of zmizla in developing zebrafish larvae results in lethality at $15 \mathrm{dpf}$ and delayed erythroid maturation. Differential gene expression analysis indicated that $15 \mathrm{dpf}$ zmizla-null larvae had altered expression of autophagy genes, and erythrocytes that lacked Zmizla function exhibited an accumulation of mitochondrial DNA. Furthermore, we observed that autophagy gene expression was dysregulated at earlier stages of development, which suggests the involvement of Zmizla in the regulation of autophagy genes beyond the process of red blood cell differentiation. Finally, we showed that the loss of Zmizla decreased the capacity of the embryos to respond to vitamin $\mathrm{D}$, indicating additional participation of Zmizla as a mediator of vitamin $\mathrm{D}$ activity. 


\section{Introduction.}

Hematopoiesis in zebrafish is a highly conserved developmental process. Both the morphology of hematopoietic cell types and the genetic mechanisms involved in the differentiation of blood cells share striking similarities with those processes described in the mammalian models. Similar to higher vertebrates, zebrafish undergo two waves of hematopoiesis: primitive and definitive [1-3]. Primitive hematopoiesis initiates in embryos at approximately 12 hours postfertilization (hpf) with the detection of hemangioblasts that are positive for gatal. Hemangioblasts are progenitor cells derived from the ventral mesoderm that arrange in two parallel stripes along the posterior trunk. Later, these cells migrate to the posterior part of the intermediate cell mass (ICM), a tissue that extends along the trunk between the notochord and the yolk sac, where they develop into erythroid cells. By $24 \mathrm{hpf}$, primitive erythroblasts enter the circulation and account for the blood function for at least 4-5 days, when erythrocytes derived from the definitive wave incorporate into the blood [1, 4-6]. Definitive hematopoiesis is initiated in 26-28 hpf embryos in the region located between the axial vein and the dorsal aorta. Hematopoietic self-renewing progenitor cells (HSPCs) are generated by transdifferentiation from endothelial cells of the ventral aorta in a process that is known as endothelial-to-hematopoietic transition [7-9]. HSPCs generate pluripotent hematopoietic stem cells (HSCs), which have the potential to differentiate into all blood cell types and are recognized by the expression of runxl and cmyb. As they originate, HSCs enter the circulation and start a migration that sequentially seeds the locations where different lineages will be produced $[3,5,6]$. By 48 hpf, HSCs reach the caudal hematopoietic tissue through the axial vein. Six hours later, they arrive in the thymus, which is an exclusive site for the production of T lymphocytes, and by $4 \mathrm{dpf}$, HSCs colonize 
the kidney marrow, which becomes the main organ for hematopoiesis in adults throughout the lifespan.

Pluripotent HSCs give rise to progenitors of different lineages, including erythroidcommitted progenitors. In humans, erythroid progenitors are classified according to their in vitro colony-forming properties into burst-forming unit-erythroid (BFU-E) cells and colonyforming unit-erythroid (CFU-E) cells. CFU-E cells undergo three to five divisions during their differentiation and ultimately produce mature erythrocytes [10]. In zebrafish, erythrocyte maturation starts with the generation of proerythroblasts, cells with a strong basophilic cytoplasm and granular nuclei. Maturation involves the progressive acidification of the cytoplasm, the condensation of nuclear chromatin, the loss of mitochondria and a reduction in cell diameter. Mature fish erythrocytes are elongated cells that conserve a small nucleus [11]. The key factor that controls the gene transcription programs required for the terminal differentiation of erythroid cells is Gata-1 [12].

Human ZMIZ1 protein was initially identified as an androgen receptor (AR) coactivator [13]. Analysis of its sequence revealed the presence of several important functional domains, including a tetratricopeptide repeat (TPR) at the N-terminus extremity, an alanine-rich motif predicted to be intrinsically disordered, and two proline-rich domains, one of them within the C-terminus, containing a strong transactivation activity (TAD) and a SP-RING/Miz domain, which is highly conserved in members of the PIAS family and confers SUMO-E3-ligase activity to the PIAS proteins $[14,15]$.

In addition to coactivating the transcription mediated by the $\mathrm{AR}, \mathrm{Zmizl}$ is known to coactivate p53, Smad3 and Notch signaling [16-18]. Importantly, it has been shown that during $\mathrm{T}$ cell development in mice, Zmizl promotes normal and leukemic pre-T-cell proliferation. For this function, Zmiz1 interacts directly with Notch1 through its N-terminal 
domain (the TPR) and regulates more than $40 \%$ of Notch-induced target genes [18]. Consistently, mutagenesis screens implicated ZMIZ1 as a NOTCH1 collaborator in human T-cell acute lymphoblastic leukemia [19]. Further associations of ZMIZ1 with severe human diseases have been discovered in several GWAS and case studies. In particular, hZMIZ1 is a risk factor for several autoimmune conditions. Among the traits that have been associated with ZMIZ1 are multiple sclerosis (MS) [20-22], Crohn's disease [23-25], inflammatory bowel disease $[26,27]$, celiac disease [28, 29], psoriasis [25], vitiligo [30, 31] and dysmenorrhea [32]. Interestingly, the regulation of ZMIZ1 by vitamin D appears to contribute to autoimmunity. Additional GWAS studies found ZMIZ1 to be a risk allele for type 2 diabetes [33, 34], and in other genomic screens, ZMIZ1 has been identified as an oncogene implicated in breast [35, 36], epithelial and colorectal cancer [37-39]. Finally, in a recent study, Carapito et al. found that ZMIZ1 variants with mutations that affect key protein regions cause a syndromic neurodevelopmental disorder [15]. Notably, in these studies, ZMIZ1 expression was found downregulated in autoimmune disorders, whereas it was found upregulated in cases of cancer, which highlights the importance of the precise regulation of ZMIZ1 expression in human cells.

The multiple phenotypes produced by abnormalities in ZMIZ1 expression are not surprising considering the various functional domains of ZMIZ1, which entail a diversity of potential interactions with a broad range of transcription factors. Therefore, an important role of ZMIZ1 during embryonic development was anticipated. On this subject, it was shown that mice homozygous for a mutation in Zmizl die at mid-gestation due to yolk sac vascular remodeling failure and abnormal embryonic vascular development [40].

In this study, we used zebrafish to analyze the roles of Zmizla during embryonic development. Zebrafish present advantages for studies involving cardiovascular or blood 
phenotypes since their oxygen homeostasis is independent of blood circulation, and thus, they can form organs in the absence of a functional cardiovascular system. We obtained CRISPR/Cas9 zmizla mutant fish and found that in the absence of Zmizla, most of the larvae die between 15-20 dpf, whereas approximately 30\% survive to adulthood. Homozygous mutant larvae displayed abnormalities in definitive erythropoiesis, which consists of delayed erythroid maturation observed from $11 \mathrm{dpf}$, reaching its maximum penetrance at $15 \mathrm{dpf}$, when embryos started to die. Transcriptomic analysis of the mutants indicated that the gene groups with the highest enrichment of differentially expressed genes (DEGs) were those associated with autophagy, mitochondrion organization and the biosynthesis and metabolism of sterols and steroids. We show that circulating erythropoietic cells in the zmizla mutant contain increased copy numbers of mitochondrial DNA, suggesting a defective elimination of mitochondria. Additionally, we found that autophagy gene expression is altered in the mutant embryos starting in the early stages, which suggests a role of Zmizla in the regulation of autophagy genes beyond the process of red blood cell differentiation. Finally, we studied the vitamin D response in zmizla mutants and found a reduced capacity of the $z m i z 1 a^{-/}$embryos to respond to calcitriol treatment. This last finding is consistent with the previous findings that indicate a relevant participation of Zmizla in the immune response.

\section{Materials and methods}

\subsection{Fish maintenance and strains}

A zebrafish (Danio rerio) AB-TU-WIK hybrid line was used. The embryos were obtained by natural crosses and raised at $28^{\circ} \mathrm{C}$ based on standard procedures [41]. The staging was performed according to the Kimmel system [42]. Zebrafish transgenic lines $\operatorname{Tg}(m p x: g f p)^{i 114}$ and $\operatorname{Tg}($ mpeg 1:EGFP)gl22 used respectively for neutrophile and macrophage lineage tracking 
(Renshaw y Ellet), were generously donated by Dr. Herman Spaink. Zebrafish were handled in compliance with local animal welfare regulations and all experimental protocols were approved by the Comité de ética (Instituto de Biotecnología, UNAM).

\subsection{In situ hybridization}

The RNA in situ hybridization using DIG-labeled antisense RNA probes was performed according to reported standard protocols [43]. The plasmids used for in situ probe synthesis were previously described and generously donated as follows: gatal by Leonard Zon [44], runx by Katherine Crosier [45] and ragl by Catherine Willett [46]. For synthesis of the zmizla in situ probe the zmizla fragment from 1078 to 1747 from the cDNA sequence was cloned and transcribed.

\subsection{CRISPR/Cas9-mediated mutations and genotyping}

CRISPR/Cas9 target sites were designed using an online tool ZiFiT Targeter software (http://zifit.partners.org/ZiFiT). The zmizla genomic target sequence is 5'GGACCTCGGCTACCGGCTTCTGG3', located at exon 3. The primers 5'AAACGAAGCCGGTAGCCGAGGT3' and 5'TAGGACCTCGGCTACCGGCTTC3' were annealed and cloned into the pDR274 plasmid [47]. sgRNA was synthesized using T7 RNA polymerase (Roche). AmpliCap SP6 High Yield Message (CellScript) was used for the Cas9 mRNA synthesis using the pCS2-nls-zCas9-nls plasmid [47]. One-cell stage embryos were injected directly into the cell with $\sim 10 \mathrm{ng} / \mu \mathrm{l}$ of $\operatorname{sgRNA}$, and $\sim 40 \mathrm{ng} / \mu \mathrm{l}$ of Cas $9 \mathrm{mRNA}$ diluted in $100 \mathrm{mM} \mathrm{KCl}$. Embryos injected only with Cas9 were used as controls.

The targeted genomic locus was amplified with Phusion High-Fidelity DNA Polymerase (Thermo) from single embryos or larvae using primers that anneal to sites 50 and $385 \mathrm{bp}$ 
upstream and downstream from the target site respectively (see supplementary table 1). The PCR product was cloned into a pJet1.2 plasmid (Thermo Scientific) for sequencing. Primers flanking the target site were used to amplify a 252 bp fragment for genotyping (supplementary table 1).

\subsection{Survival Assay}

Crosses from zmizla+/- fishes were raised at $28^{\circ} \mathrm{C}$ with a density of a hundred larvae per $300 \mathrm{ml}$. From each cross 20 larvae were sampled at each time point 1, 9, 11, 13, 15, 17 \& 19 dpf for genotyping. Surviving larvae were calculated based on the distribution of genotypes. The survival difference and statistical significance were determined by a log-rank test.

\subsection{Histology}

After in situ hybridization, embryos were fixed overnight at $4{ }^{\circ} \mathrm{C}$ in Bouin's solution and dehydrated by a series of graded ethanol. Samples were embedded with paraffin after xylene. Tissue sections of $10 \mu \mathrm{m}$ were cut and stained in hematoxylin-eosin based on a reported protocol [48]. Subsequently, sections were mounted and photographed on a Leica DMLB microscope equipped with an AxioCam MR5 (Zeiss) camera.

\subsection{Microscopy and analysis}

For live imaging, embryos were anesthetized using 0.016\% tricaine (Sigma). Both live and fixed embryos were mounted in $0.6 \%$ low-melting agarose. Fluorescent and brightfield image acquisition was performed using a Leica DMLB 100S stereoscope. For erythrocytes slides image acquisition was performed on a Leica MZ12S microscope under Normarski 
illumination. Images were processed with Infocus and ImageJ software. Images were adjusted for brightness and contrast using Image $\mathrm{J}$.

\subsection{Embryonic Blood Collection and Morphometry}

Embryonic zebrafish erythrocytes at indicated times after fertilization were collected by transecting tails of 10-12 embryos in $20 \mu \mathrm{L}$ of PBS. Larvae were anesthetized and left to bleed for 5 minutes before collecting the bodies for genotyping. Slides were prepared and stained with Wright/Giemsa stain (Hycel) according to the manufacturer's instructions. Embryonic erythrocytes were stained with hemoglobin-specific O-dianisidine (SigmaAldrich) staining as described previously [49]. Nuclear and cytoplasmic areas of 60-80 randomly selected erythrocytes were measured by using Image $\mathrm{J}$ software, and the $\mathrm{N}: \mathrm{C}$ area ratio was calculated.

\subsection{RNA-sequencing and data analysis}

Pools of twenty $15 \mathrm{dpf}$-embryo (zmizla $a^{+/-}$and $\left.z m i z l a^{--}\right)$were used for total RNA isolation with RNAeasy columns (Qiagen) from five independent crosses. Each RNA sample was analyzed for quantity and purity with Agilent 2100 Bioanalyzer (Agilent Technologies, CA, USA). RNA samples were used for RNA sequencing (4 control $z m i z 1 a^{+/}$embryos and 3 $z m i z 1 a^{-/-}$mutant embryos). RNA sequencing and data analysis were performed by Novogene Co., Ltd. According to their protocols, sequencing libraries were generated using NEBNext ${ }^{\circledR}$ Ultra $^{\mathrm{TM}}$ RNA Library Prep Kit for Illumina ${ }^{\circledR}$ (NEB, USA) following the manufacturer's recommendations, and index codes were added to attribute sequences to each sample. Library preparations were sequenced on an Illumina platform and $125 \mathrm{bp} / 150 \mathrm{bp}$ paired-end reads were generated. Raw reads were filtered into clean reads aligned to the 
reference sequences. The alignment data was utilized to calculate the distribution of reads on reference genes and mapping ratio. The fragments per kilobase of transcript per million mapped reads (FPKM) method was used to calculate the expression levels. Differential expression analysis between two groups ( $\geq$ three biological replicates per condition) was performed using the DESeq2 R package (1.14.1). The resulting P-values were adjusted using the Benjamini and Hochberg's approach for controlling the False Discovery Rate (FDR). Genes with an adjusted P-value $<0.05$ found by DESeq2 were assigned as differentially expressed.

Gene Ontology (GO) enrichment analysis of differentially expressed genes was implemented by the clusterProfiler R package, in which gene length bias was corrected $[50,51]$. GO terms with corrected P-value less than 0.05 were considered significantly enriched by differential expressed genes. KEGG is a database resource for understanding high-level functions and utilities of the biological system, such as the cell, the organism, and the ecosystem, from molecular-level information, especially large-scale molecular datasets generated by genome sequencing and other high-throughput experimental technologies (http://www.genome.jp/kegg/) [52]. We used clusterProfiler R package to test the statistical enrichment of differential expression genes in KEGG pathways.

\subsection{Real-time qPCR analysis}

For standard experiments, groups of approximately twenty embryos were collected and transferred to RNAlater (Qiagen). The following day the RNA was extracted with RNAeasy columns (Qiagen) following the manufacturer's instructions. For the calcitriol induction experiments, 5-7 halves of embryos were pooled after genotyping. $500 \mathrm{ng}$ was used for reverse transcription with Revertaid M-MLV (Invitrogen) with random primer decamers. 
cDNA (or DNA for the mitochondrial quantification assay) was diluted 1:40 in $15 \mu 1$ quadruplicate reactions. The Maxima SYBR Green Reagent (Thermo) was used for qPCR in a Light Cycler 480 (Roche), using the following program: $95^{\circ} \mathrm{C}, 5 \mathrm{~min} ;\left(95^{\circ} \mathrm{C}, 15 \mathrm{~s} ; 58^{\circ} \mathrm{C}\right.$, $20 \mathrm{~s} ; 72{ }^{\circ} \mathrm{C}, 30 \mathrm{~s}-$ single quantifications at this step-) $\times 50$ cycles; and a melting curve from 72 to $95{ }^{\circ} \mathrm{C}$ holding during $5 \mathrm{~s}$ each $0.5{ }^{\circ} \mathrm{C}$ was performed. Relative quantification with the Light Cycler 480 software was performed with at least three of the four replicates that displayed similar reaction curves, after normalizing to the expression level of the elongation factor 1 alpha (eflalpha) and using a double delta $\mathrm{Ct}$ method. The primer sequences are listed in supplementary table 1 .

\subsection{Mitochondrial quantification}

Mitochondria were quantified on extracted erythrocytes by measuring the number of copies of mitochondrial DNA per genomic DNA. The erythrocytes were extracted as previously described and lysed for DNA extraction. The samples were used for genotyping and diluted 1:100 prior to qPCR quantification. For the absolute quantification of mitochondrial/nuclear DNA ratio, relative values for the mitochondrial gene (mt-ndl) \& the genomic gene (poll) were compared within each sample to generate a ratio representing the relative level of mitochondrial DNA per nuclear genome. The primers are shown in supplementary table 1.

\subsection{1. $m R N A$ synthesis and rescue experiments}

The PCMVSPORT3.1 plasmid containing the cDNA of zmizla (Dr.77379 I.M.A.G.E consortium) was used for mRNA synthesis with the mMessage mMachine SP6 kit (Ambion). Previous to the rescue assays 100,400 , and 800 pg of zmizla mRNA were separately injected into wild-type embryos to generate a dosage-response curve. The optimal amount of mRNA 
that did not produce a significant number of dead or defective embryos in comparison to buffer-injected controls was $400 \mathrm{pg}$. For the subsequent experiments, one-cell stage embryos obtained from heterozygous crosses were injected with $400 \mathrm{pg}$ of zmizla mRNA.

\subsection{Vitamin D response assay}

24 hpf embryos from a zmila+/- cross were manually dechorionated and placed in a 24 well plate. Two embryos were placed per well for a total of 24 per condition in either control or $10 \mu \mathrm{M}$ calcitriol $(1,25(\mathrm{OH}) 2 \mathrm{D})$ solution (Caiman chemical) and incubated for 24 hours. Embryos were collected and cut in half using the tail for genotyping, then pooled according to genotype, and used for RNA extraction and reverse transcription. After cDNA synthesis, the expression levels of cyp24al were determined by qPCR.

\section{Results}

\section{1. zmizl gene in zebrafish}

Human ZMIZ1 is homologous to the ZMIZ2 protein whose functions we reported previously for its ortholog during zebrafish development. ZMIZ2 conserves the functional domains described for ZMIZ1, and in the vicinity of the SP-RING/Miz domain, it shares a similarity beyond the $\mathrm{Zn}$ finger $[53,54]$. This extended domain is known as the X-SPRING (eXtended SP-RING). X-SPRING defines the ZMIZ proteins that are conserved in evolution in several animals from insects to humans. In zebrafish, two zmizl genes encode the Zmizla and Zmiz1b proteins. Zmizla shares a sequence identity of $83 \%$ with human ZMIZ1, whereas Zmizlb is $64 \%$ homologous. The homology between the two Zmiz1 fish proteins is $63 \%$. Because Zmizla is more conserved and its expression in embryos is higher, we focused on 
the functional characterization of this gene. We used a full-length zmizla cDNA construct to examine the spatiotemporal expression pattern during zebrafish embryogenesis using wholemount in situ hybridization (WISH) (Supplementary Fig. 1). The earliest detection of zmizla transcripts was in the neuroectoderm at $75 \%$ epiboly. At somite-stages, zmizla was mainly expressed in the neural regions, tip of the tail and optic primordium. At 24 hpf, zmizla transcripts were detected in the midbrain, spinal cord, and optic stalk. In addition to these locations, at $36 \mathrm{hpf}$, we detected additional expression of zmizla in the floor plate and the pectoral fin buds. Histological sections of embryos at 24, 48 and $72 \mathrm{hpf}$ revealed the presence of zmizla transcripts in the retina, midbrain and hindbrain, gut and circulatory system (Supplementary Fig. 1H-J).

\subsection{Loss of zmizla led to embryonic death at $15 \mathrm{dpf}$}

To introduce CRISPR/Cas9-mediated mutations in the zmizla gene, we designed a guide RNA (gRNA) that targeted exon 3 of the reported genomic sequence. Frameshift mutations in this exon created a premature stop codon leading to a truncated protein (80 aa) lacking all functional domains of Zmizla except for a small part of the TPR (Fig. 1A). We obtained two mutant alleles with 7- and 22-nucleotide deletions. Crosses of the F1 expanded lines from these alleles produced offspring in which embryos homozygous for the mutation were present at Mendelian frequencies. They did not exhibit any morphological abnormalities. Two groups of $z m i z 1 a^{+/+}$and $z m i z l a^{-/-}$fish were compared to test for differences in survival during development. Up to $14 \mathrm{dpf}$, there was no difference in survival between mutants and wild types. However, at $15 \mathrm{dpf}$, zmizl $1 a^{-/}$larvae showed a dramatic drop in the survival rate compared to $z m i z l a^{+/+}$larvae (Fig. 1B). A steady decline in $z m i z l a^{-/}$larvae was detected up to $19 \mathrm{dpf}$, when $30 \%$ of mutant larvae were still alive. Surviving larvae reached adulthood 
and seemed normal, except for a reduced fertility observed in homozygous females. This survival behavior was the same for both alleles as well as for a heteroallelic combination. Thus, we continued the work with the 22-base pair deletion.

\section{3. zmizla mutants have delayed erythrocyte maturation}

Since we found reports describing phenotypes of death at similar ages for zebrafish mutants affected by hematopoiesis defects, we analyzed the possibility of an abnormal hematopoiesis in the $z m i z l a^{-/}$fish. Prior to the search for a phenotype in developing hematopoietic cells, we confirmed the presence of zmizla transcripts in the circulating erythrocytes in embryo sections of WISH experiments at 24 and $48 \mathrm{hpf}$, and we detected a positive signal in red blood cells (Fig. 2). We then examined erythrocyte development in zmizla mutants. For this purpose, we collected erythrocytes from larvae after transecting their tails. We compared stage-specific erythrocytes from wild-type and zmizla-mutants at 3, 7, 11 and $15 \mathrm{dpf}$. Wright-Giemsa staining of blood smears revealed delayed maturation in the zmizla-null erythrocytes from 11 and $15 \mathrm{dpf}$ larvae (Fig. 3A). Mutant larvae at these stages presented a percentage of basophilic blood cells with large nuclei resembling proerythroblasts. To quantify the delay of maturation, we measured the nucleus-to-cytoplasm $(\mathrm{N}: \mathrm{C})$ ratio and found that this value was significantly higher in the 11 and 15-dpf zmizl-mutated erythrocytes (Fig. 3B).

To evaluate whether the zmiz1-nule embryos carried hemoglobin deficiencies, we stained isolated erythrocytes from wild-type and mutant $15 \mathrm{dpf}$ embryos with $O$-dianisidine $(O$-das) and found that they all showed similar intensities, which indicated a normal hemoglobinization (Fig. 4A). However, whole embryo $O$-das staining (at $48 \mathrm{hpf}$ ) showed that while the intensity of the signal was similar in wild-type and mutant embryos, there was 
a difference when we measured the yolk-stained area, which was significantly smaller in the zmizla-mutant embryos (Fig. 4B). A possible interpretation of this result is that circulating erythrocytes are distributed differently along the embryo or in the yolk in the control and mutant embryos.

\subsection{Primitive hematopoiesis and HSC specification are normal in zmizla mutants}

To analyze whether primitive hematopoiesis was defective in the zmizla mutant embryos, we examined the expression pattern of gatal in embryos at 18 to $30 \mathrm{hpf}$ (Supplementary Fig. 2); we found that gatal is normally expressed at early stages. At $30 \mathrm{hpf}$, mutant embryos exhibited substantial numbers of positive cells throughout the yolk sac, which were not detected in control embryos (Supplementary Fig. 2E-F). This increased signal could reveal the presence of migrating gatal-expressing progenitors in the mutants and it might be correlated with the abnormal $O$-das staining found in $48 \mathrm{hpf}$ mutant embryos. Apart from this observation, the specification of primitive erythrocytes seems normal in the zmizla mutants. To analyze if hematopoietic stem cells were produced in the zmizla mutant embryos, we examined runxl expression in $30 \mathrm{hpf}$ and $5 \mathrm{dpf}$ embryos. WISH revealed a normal runxl pattern in the zmizla mutants, indicating the presence of HSCs (Supplementary Fig. 2G-J). To further test whether definitive hematopoietic cells in the zmizla mutants were able to undergo lymphoid differentiation, we examined ragl expression at 5dpf. Both, control and mutant embryos showed a ragl positive signal in the thymus, indicating that a proper T-cell development occurred in the zmizl embryos (Supplementary Fig. 3A-B). Finally, we assessed the formation of myeloid cells in $z m i z 1^{-/-}$embryos. For this purpose, we used zebrafish transgenic lines with green fluorescent neutrophils expressing $\operatorname{Tg}(m p x: e G F P)^{i 114}$ or red fluorescent macrophages expressing $\operatorname{Tg}(m p e g 1: m C h e r r y)^{g l 22}$ to visualize these cells in 
control and mutant embryos. We found an apparently normal abundance of both neutrophils and macrophages in 4pdf zmizla embryos compared with control embryos (Supplementary Fig. 3C-F). Altogether, our analysis showed that the zmizla mutants have a normal primitive and definitive hematopoiesis and proper myeloid and lymphoid differentiation, which indicates that the defects observed during the maturation of erythrocytes are independent of these processes.

\subsection{RNA-seq analyses revealed the downregulation of autophagy genes in the Zmizla mutant}

To develop a comprehensive characterization of Zmiz1-mutant embryos, we examined global differences in gene expression. To this aim we conducted transcriptome sequencing (RNA-seq) analysis of $15 \mathrm{dpf} z m i z l a$-mutant and wild-type embryos. Pearson correlation between samples (Supplementary Fig. 4A) and heat map analysis (Fig. 5A) showed clustering of three mutant and four wild-type biological replicates of each population, demonstrating that the two embryo groups are distinct. Differential expression analysis uncovered 2892 differentially expressed genes (DEGs), of which 1309 were upregulated and 1583 were downregulated (Fig. 5B). Through Gene Ontology (GO) classification, we found that DEGs were enriched for the biosynthesis and metabolism of sterols and steroids, mitochondrial organization and autophagy (Fig. 5C). In the cellular component terms, the zmizla mutation was significantly associated with the endoplasmic reticulum, mitochondria and autophagosomal components (Supplementary Fig. 4B). Notably, the autophagy genes were mostly downregulated (Fig. 5E). This is evident in the Kyoto Encyclopedia of Genes and Genomes (KEGG) analysis, where we found that the top enriched pathways for the downregulated DEGs were those related to animal autophagy (Fig. 5D). 
The RNA-seq data involving autophagy and erythropoiesis genes were validated by real-time polymerase chain reaction (qPCR). This analysis confirmed the downregulation of $u l k l a$, bnip4, $\operatorname{atg} 9 a$ and $\operatorname{atg} 13$ in the Zmizla-mutants compared to control larvae (Fig. 6A). Autophagy is a catabolic pathway that is the main mechanism responsible for the removal of organelles during red blood cell development. In particular, mitochondrial clearance by mitophagy is an essential step for terminal erythroid differentiation [55, 56]. Mice with deletions in autophagy genes retain mitochondria in mature erythrocytes and display anemia and reticulocytosis [57]. In zebrafish mitophagy is also the primary method used to eliminate mitochondria from erythroblasts [58]. To evaluate the clearance of mitochondria in the zmizla mutants, we determined the ratio between mitochondria (mt-DNA) and nuclei (nDNA) in circulating erythroid cells isolated from 15 dpf larvae. For this purpose, we used qPCR to measure the levels of the NADH dehydrogenase 1 (nd1) gene, encoded in the mitochondrial genome, which we normalized to the DNA levels of the nuclear-encoded DNA polymerase gamma (polgl) gene [59]. This analysis indicated an increased mt-DNA copy number in the zmizla mutants relative to the wild-type blood cells (Fig. 6B). This result, together with the reduced expression of autophagy genes in the mutant embryos, suggests that the delayed maturation detected in the red blood cells (RBCs) of the zmizla mutant could be due to impaired mitophagy which leads to the retention of mitochondria.

To determine whether the altered expression of autophagy genes represented a general defect in the zmizl mutants not specifically related to the removal of organelles during RBCs maturation, we analyzed the expression of autophagy genes in $48 \mathrm{hpf}$ mutant and wild-type embryos. We found significantly altered expression of autophagy genes, although with the opposite tendency, with the upregulation of ulkla and gabarapb (Fig. 6C). To demonstrate the specificity of the zmizla knockout phenotype, we performed a rescue experiment to prove 
that the alterations in gene transcription found in the mutant embryos were due to the loss of Zmizla function. We injected single-cell embryos obtained from $z m i z 1 a^{+/-} z_{m i z} 1 a^{-/-}$crosses with synthetic zmizla mRNA and collected them at $48 \mathrm{hpf}$. After genotyping, pools of $z m i z l a^{+/-}$and $z m i z l a^{-/-}$embryos were used for quantification of gabarapb gene expression. We found that zmizla $a^{-/}$embryos injected with zmizla RNA recovered gabarapb expression levels, which were upregulated in the mutants (Fig. 6D). Thus, gabarapb upregulation is a consequence of a lack of Zmizla activity. Collectively our results show that Zmizla is required for the correct expression of the autophagy genes in zebrafish.

3.6. The zmizla mutants exhibit alterations in proinflammatory gene expression and a reduced response to vitamin $D$

Autophagy is known to contribute to the regulation of inflammation and immune system function. In particular, impaired mitophagy causes mitochondrial dysfunction, increased oxidative stress and susceptibility to proinflammatory stimuli $[60,61]$. In light of this information, we decided to quantify proinflammatory gene expression in the zmizla mutant fish. We performed qPCR to compare the expression of the inflammatory cytokines $i l 1 b, I l 6$, caspase- 1 and thfa in 48 hpf mutant and control embryos. We found a significant upregulation of the $i l l b$ gene in the $z m i z l a^{-/}$embryos, while tnfa exhibited a significant downregulation (Fig. 7A). This result suggests that the zmizla mutant fish might have abnormal inflammatory responses.

Human ZMIZ1 is a LDAD risk gene. In particular for multiple sclerosis (MS), both ZMIZ1 gene transcription and protein levels are reduced in blood in people with MS, and ZMIZ1 is regulated by vitamin $\mathrm{D}$ in monocytes [22]. The vitamin $\mathrm{D}$ receptor (VDR) binds to superenhancer regions in the ZMIZ1 gene in immune cells, and single nucleotide 
polymorphisms (SNPs) associated with risk were mapped to the VDR binding peaks [21]. These results support the use of ZMIZ1 gene expression as a biomarker for MS. Furthermore, it was suggested that higher expression of ZMIZ1 in response to vitamin D results in protection across LDADs. Therefore, the manipulation of ZMIZ1 expression in a model system could be a useful tool for the study of LDADs pathogenesis.

In our RNAseq study, the top terms of the GO BP analysis included the enrichment of "steroid biosynthesis", and some DEGs in this term were related to the vitamin D pathway, including $p t h 1 a$, tmsf2, ebp, $h s d 17 b 7, s c 5 d$, and $f b p l b$ (Supplementary Fig. 4C). Considering these data, we decided to evaluate the response to vitamin D in live zebrafish zmizla mutants. To visualize vitamin D signaling activity, we incubated $24 \mathrm{hpf}$ control and mutant embryos in the presence of $1,25(\mathrm{OH}) 2 \mathrm{D} 3$ (calcitriol), which is the active hormone derived from vitamin D that binds to the VDR. After one day of treatment, we quantified the expression of cyp24a1. Cyp24a1 is the cytochrome 450 enzyme that specializes in the degradation of calcitriol and is the most highly induced vitamin D target gene; thus, it is a good indicator of the vitamin D signaling activity [62]. We found that in the control embryos, calcitriol induced up to a hundred-fold change in the expression of cyp24al. This stimulation was greatly reduced in the zmizla mutants, which showed $60 \%$ less stimulation of cyp $24 a 1$ expression compared to control embryos (Fig. 7B). This result indicates that Zmizla is required for an optimal response to vitamin D.

\section{Discussion}

In this study, we analyzed the phenotype produced by the loss-of-function of zmizla gene in zebrafish. ZMIZ1 is a transcriptional coactivator that contains a variety of structural domains. These features enable a diversity of molecular interactions that could allow this protein to 
participate in different biological functions. We found that zmizla mutant embryos at $11 \mathrm{dpf}$ had immature erythroblasts in their blood, which indicates a defective terminal differentiation of their definitive erythrocytes. Our RNA-seq study uncovered the downregulation of the autophagy genes $u l k 1$, atg13, bnip4, and $\operatorname{atg} 9 a$. Ulk1 is a serine-threonine kinase that lies on top of the autophagy pathway and initiates both canonical and ATG-5-independent autophagy. In mammals, Ulk1 plays a critical role in the clearance of mitochondria and ribosomes during the differentiation of erythroblasts, and ulk1 expression levels correlate directly with the removal of mitochondria by autophagy. Therefore, the decreased expression level of ulk1 in the zmizla mutant fish could be a cause of the delayed maturation of the erythroblasts. Studies based on the use of human erythroblast cultures show that autophagy is induced at the polychromatic erythroid stage and is accompanied by the transcriptional upregulation of several autophagy genes. GATA1 was identified as a critical factor that directly activates the transcription of autophagy genes [63]. Human ZMIZ1 is included among the GATA1 target genes in the autophagy regulatory network (ARN) database. A plausible hypothesis is that Zmizla interacts with Gatal and acts as a coactivator during the upregulation of autophagy genes. Also, p53 is well known for its role as a transcription factor that regulates autophagy. In fact, several genes encoding proteins involved in autophagy are known to be direct p53 targets. Thus, Zmizla could also participate in the regulation of autophagy through its function as a coactivator of p53. In our search for abnormal gene expression in 48 hpf Zmizl mutant embryos, we observed dysregulation of the autophagy genes ulkla and gabarapb. Interestingly, at this stage, these genes were upregulated. Altogether, the consistent alteration of the expression of autophagy genes at two different stages of development suggests that an abnormal autophagy response might be associated 
with zmizla loss-of-function and that Zmizla is involved in the regulation of Ulk1 or other autophagy genes.

A percentage of Zmizla mutant fish survive to adulthood and seem normal. This result raises the question of why adult fish might have milder or null effects in their erythropoiesis. In mice, elimination of mitochondria from embryonic reticulocytes involves the alternative Ulk1-dependent Atg5-independent macroautophagy pathway; however, primitive and adult definitive reticulocytes do not depend on this pathway for mitochondrial clearance $[64,65]$. In zebrafish, there is yet no evidence indicating the existence of the alternative autophagy pathway, nor is anything known about the types of macroautophagy operating in erythroblasts during specific stages of life. The lack of a visible phenotype in the Zmizla mutant fish could reflect that a different mechanism of mitophagy operates at adult stages, but it could also be indicative of the high capacity of erythroid cells to adapt to diminished autophagic activity during terminal differentiation.

Although human ZMIZ1 is known to coactivate transcription mediated by AR, p53, and SMAD3 in vitro, only its role in Notch signaling has been well described in vivo, in a conditional mouse model in which Zmizl was shown to act as a cofactor of Notch1 during thymocyte development and drive pre-T cell proliferation [18]. Zmizl cooperates with Notch1 to induce the Notch target genes Hes1, Lefl, and Myc. In this work, we found that zebrafish zmizla mutant embryos have normal expression of ragl in the thymus, which indicates the presence of early T-lineage progenitors. However, in our study, we did not follow the development of thymocytes during their progression throughout the different CD4-CD8 negative and positive stages in which Zmizl is also required for the Notchdependent double-negative double-positive transition [66]. Thus, the participation of Zmizla in zebrafish Notch-dependent thymocyte differentiation cannot be discarded. Zebrafish is a 
good model to analyze this question given that adaptive immune-deficient fish can reach adulthood, and unlike mouse models, can be maintained under conventional conditions [67]. Related to the coactivation of Notch1 target genes, we did not find alterations in the expression of Notch target genes in the transcriptome of $15 \mathrm{dpf}$ zmizla mutant fish or in a qPCR analysis that we performed in embryos at $48 \mathrm{hpf}$. This finding indicates that Zmizla is not a general coactivator of Notch signaling. However, these studies were performed using whole embryos, and therefore, if the coactivation effect of Zmizla is context-dependent it could be undetected.

We also found alterations in proinflammatory gene expression with the upregulation of illb and the downregulation of thfa. These findings are consistent with an altered inflammatory response in zmizla mutant embryos. Significantly, the reduced expression of ZMIZ1 in human monocytes has been associated with an increased tendency toward chronic inflammation. Inflammation is also relevant for hematopoiesis and during the terminal differentiation of erythrocytes. Tyrkalska et al. reported that in zebrafish, the inflammasome regulates the erythroid-myeloid decision in HSCs and the terminal differentiation of erythrocytes, both events occurring through the cleavage of GATA1 by Caspase-1 [68]. In our study, we did not find differential transcription of the Caspase-1, and we did not detect alterations in the number of neutrophils in 4 dpf mutant embryos; however, it would be interesting to determine the erythrocyte/neutrophil ratio and the activity of Caspase-1 in the zmizla mutants.

Finally, we discovered that Zmizla contributes to the response to vitamin D. This finding is significant because of the extensive literature that indicates a protective role of ZMIZ1 against autoimmunity. Besides, gene clusters whose expression variations correlate with the ZMIZ1 expression pattern in MS patients appear to be regulated by induced vitamin D 
superenhancers [21]. Interestingly, our result suggests the possibility of reciprocal regulation of ZMIZ1 expression and vitamin D response, implicating that the role of ZMIZ1 in autoimmunity is more important than it was considered. Thus, it will be important to determine if there are physical interactions between VDR and Zmizla and if they bind together to a particular set of genes. Several of the most upregulated DEGs identified in our RNAseq study are involved in cholesterol and vitamin D biosynthesis. This overexpression could be the result of a compensatory reaction to a VDR dysfunction. Metabolism and autophagy are both physiological processes that need to be carefully regulated to maintain cellular homeostasis. Imbalance of these processes leads to inflammation. Zmizla seems to affect the coordination of all three processes. However, there is still a lot to learn from the zmizla mutant fish. We do not yet know the molecular actions of Zmizla during the regulation of gene expression. Zmizla could operate as a coactivator that facilitates the binding of transcription factors such as Gata1, p53 or Vdr, or it could function as an E3SUMO ligase and mediate the sumoylation of these TFs. Another relevant question is whether Zmizla has independent functions in autophagy and the vitamin D response or whether the alterations in these signaling cascades are secondary to Zmizla central activity. The zmizla mutants could be a good zebrafish model for the studying the modulation of the inflammasome, the effects of vitamin $\mathrm{D}$, and its relation with disease and autoimmunity. In conclusion, in this work, we show that Zmizla is required for the maturation of embryonic definitive erythrocytes; we provide evidence of altered autophagy gene expression in $15 \mathrm{dpf}$ larvae, which potentially could cause retention of mitochondria in circulating erythroblasts; and we demonstrate that Zmizla functions to stimulate the response to vitamin D in embryos. 


\section{Acknowledgments}

We thank Drs. Leonard Zon, Katherine Crosier and Catherine Willett for kindly providing plasmids for ISH; Dr. Herman Spaink for the donation of zebrafish transgenic lines. We thank the IBT/UNAM synthesis facility for oligonucleotide synthesis, Dulce Pacheco for help with fish maintenance, and the librarian Shirley Ainsworth.

\section{Funding}

This work was supported by DGAPA-UNAM grant IN200519 and CONACyT grant 1755. F. Castillo received the CONACyT scholarship 436027.

\section{Credit author statement}

Francisco Castillo: Formal Analysis and Investigation. Laura Ramírez: Investigation. Hilda Lomelí: Conceptualization, Formal Analysis, Visualization, Supervision, Project administration, Funding, Writing- Review and Editing. 


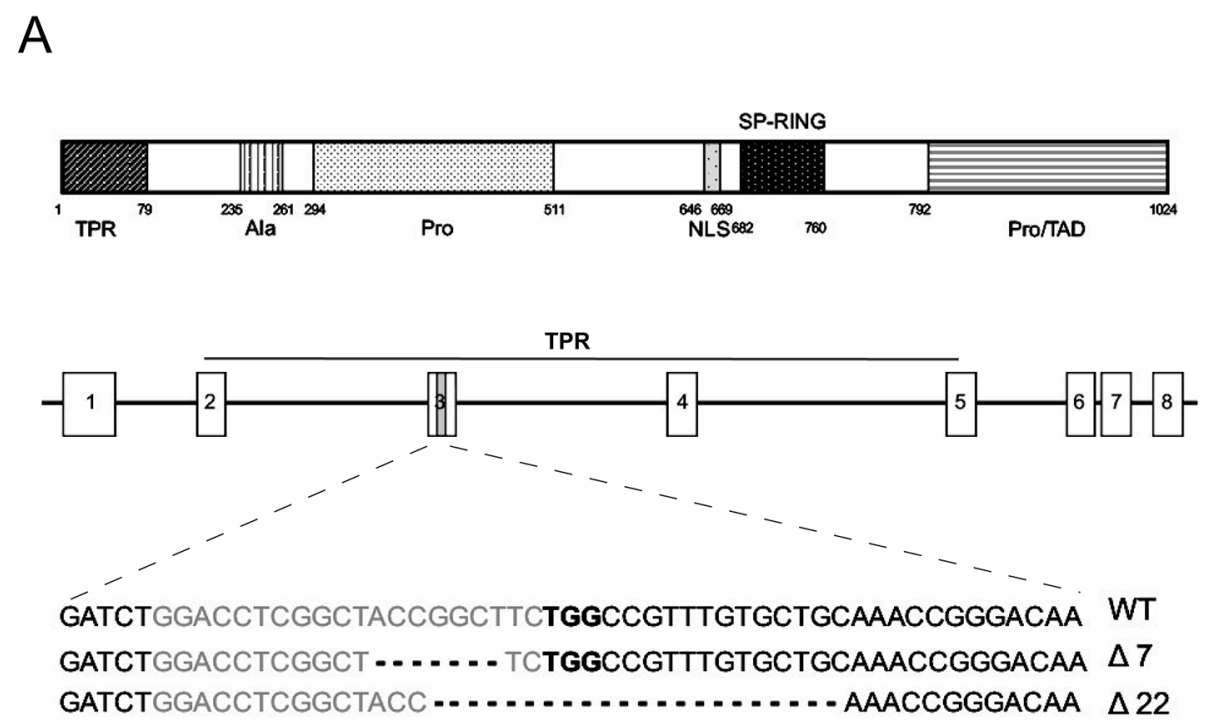

B
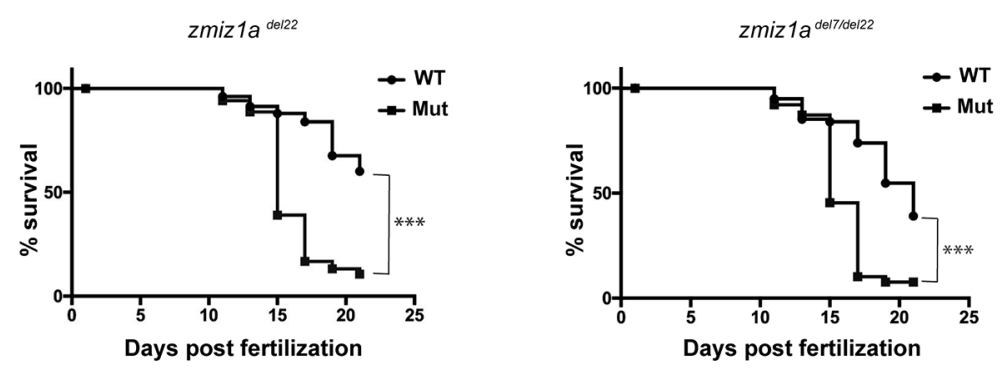

\section{Figure 1.}

A. Schematic diagram of zmizla gene. CRISPR/Cas9 mediated-deletions were produced in exon 3. The nucleotide sequence of the RNA-guide targeted region is shown in grey with the PAM in bold and the deletions are indicated in lines below. B. Survival assays for the zmizla mutant alleles. Percentage survival during the first 25 days of development is shown. Offspring from the heterozygous zmizla $a^{\text {del22 }}$ allele and the $z m i z 1 a^{\text {del7/del22 }}$ allele were compared with that of wild-type progenies. Survival curves are based on data pooled from six individual experiments $\left(z m i z l a^{d e l 22}\right)$ and three individual experiments $\left(z m i z 1 a^{\text {del7/del22 }}\right)(n$ $>100$ per group in total). The asterisks indicate the significant difference between wild-type and mutant survival $(\mathrm{P}<0.0001)$, tested with a log rank test. 

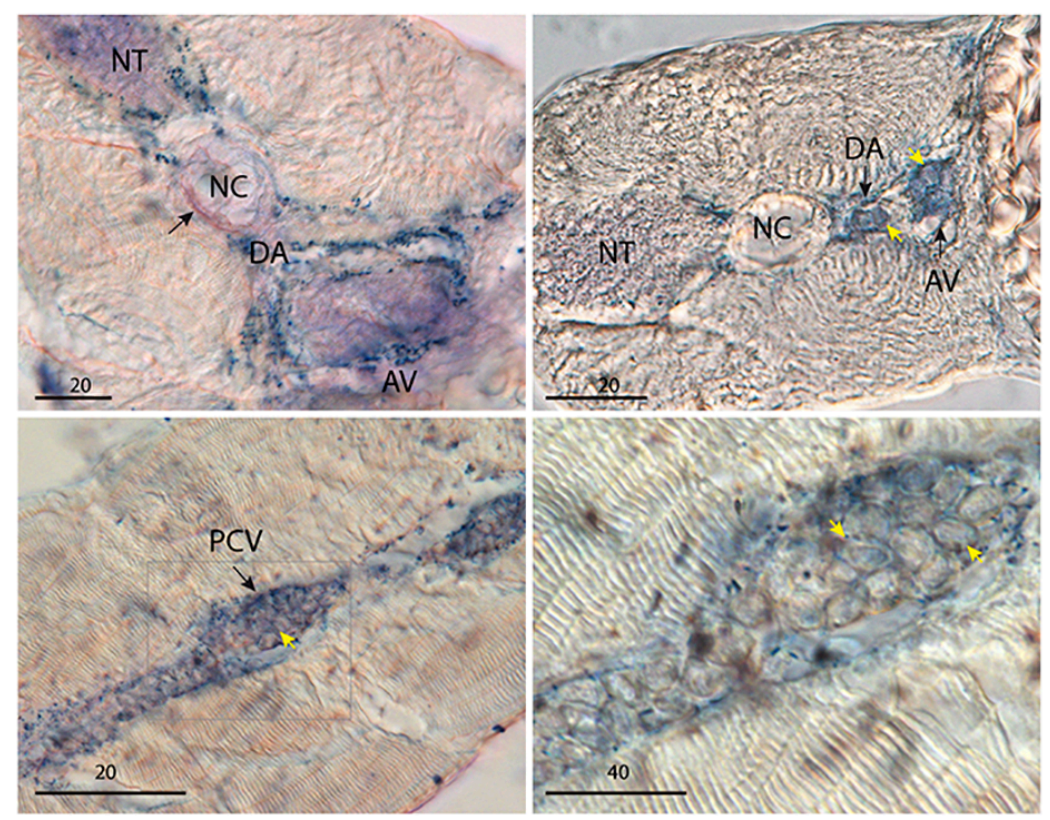

\section{Figure 2.}

Embryos showing expression of zmizla in the circulatory system. Sections of embryos after whole-mount in situ hybridization with the zmizla probe. (upper panels) Sagittal sections of 24 hpf. Scale bars: $20 \mu \mathrm{m}$. (lower panels) Sagittal sections of a $48 \mathrm{hpf}$ embryo. (Left) Scale bar: $20 \mu \mathrm{m}$. (Right) Scale bar: $40 \mu \mathrm{m}$. Yellow arrows indicate a positive zmizla signal in erythroid cells. AV: Axial Vein, DA: dorsal aorta, NC: notochord, NT: neural tube, PCV: posterior cardinal vein. 


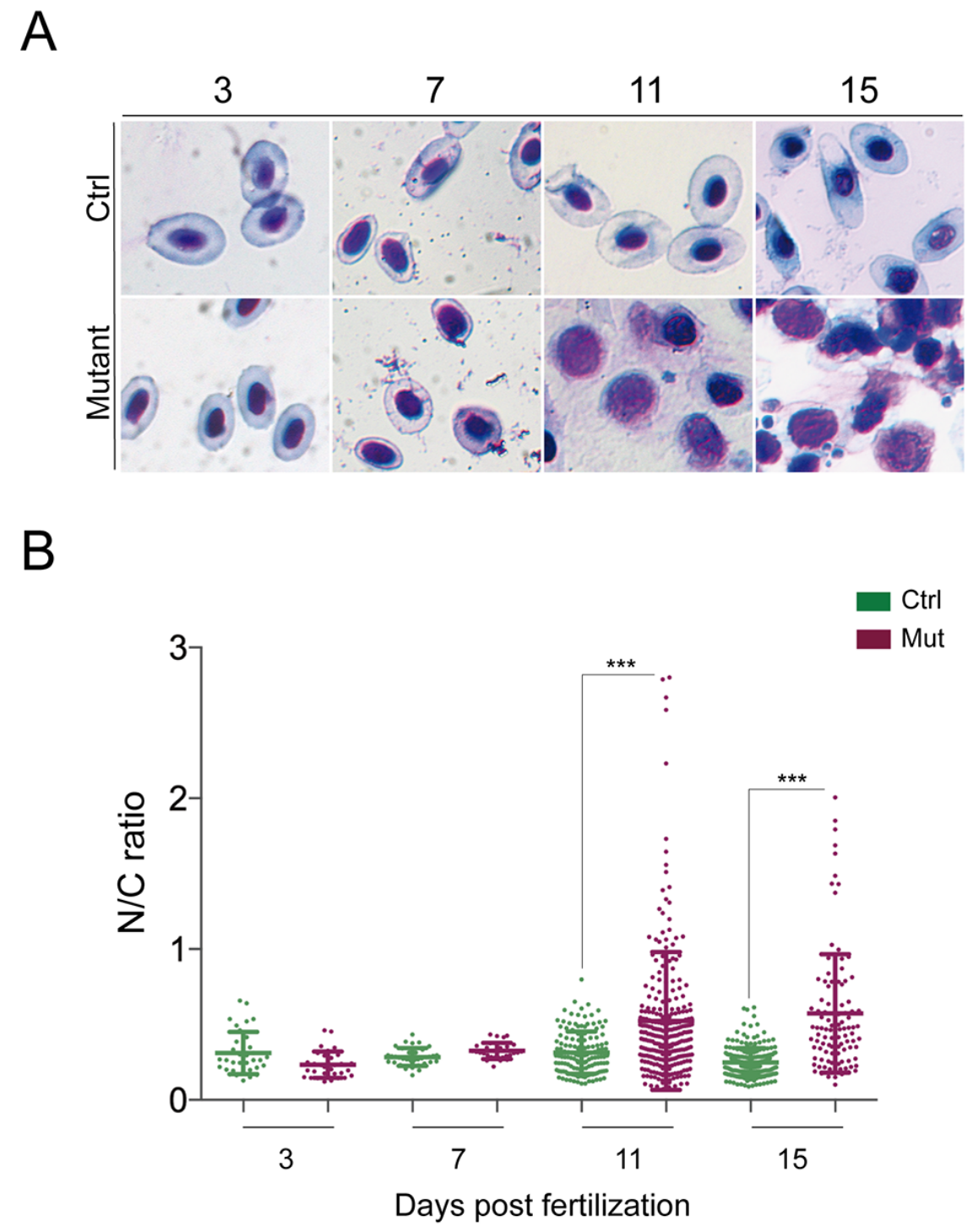

Figure 3.

Analysis of circulating erythrocytes from control and zmizla mutant embryos. A. WrightGiemsa stained isolated erythrocytes from 3, 7, 11, and $15 \mathrm{dpf}$ larvae. The presence of immature erythroblasts can be appreciated at 11 and $15 \mathrm{dpf}$. B. Scatter plots representing the tabulation of the $\mathrm{N}: \mathrm{C}$ area ratio of erythrocytes isolated from control or $z m i z 1 a^{-/-} 3$ to $15 \mathrm{dpf}$ embryos. Horizontal lines indicate mean values. Data are mean $\pm 1 \mathrm{SD}$ for $>110$ cells. $\mathrm{P}<$ 0.0001 . 

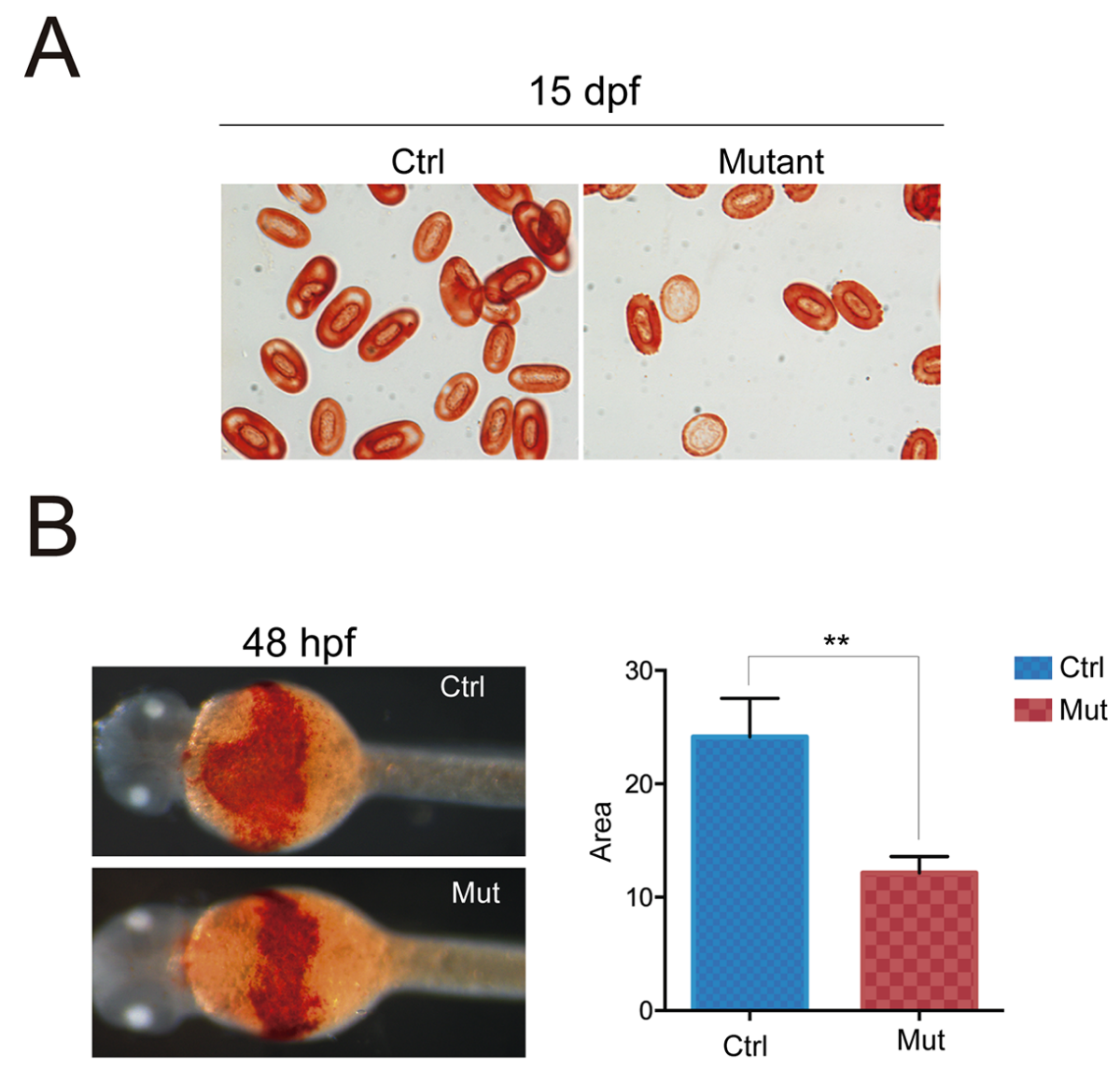

\section{Figure 4.}

Analysis of hemoglobinization of erythrocytes in the zmizla mutant embryos. A. Odianisidine (O-das) staining of isolated blood cells from $15 \mathrm{dpf}$ control and $z m i z l \mathrm{a}^{-/}$embryos shows a normal hemoglobinization of mature erythrocytes in the mutants and a weaker signal in immature erythroblasts. B. O-das staining of $48 \mathrm{hpf}$ whole embryos showing a reduced stained area in the yolk of the zmizla $a^{-/}$embryos. Data are mean \pm 1 SD for $\geq 13$ embryos. $\mathrm{P}<$ 0.001 
bioRxiv preprint doi: https://doi.org/10.1101/2021.05.14.444216; this version posted May 17, 2021. The copyright holder for this preprint (which was not certified by peer review) is the author/funder. All rights reserved. No reuse allowed without permission.

A

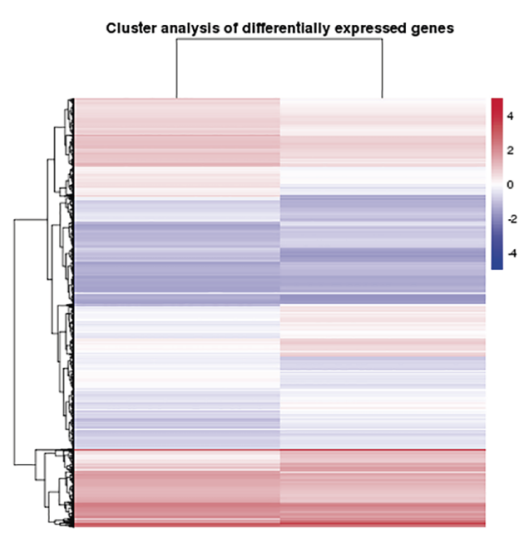

C

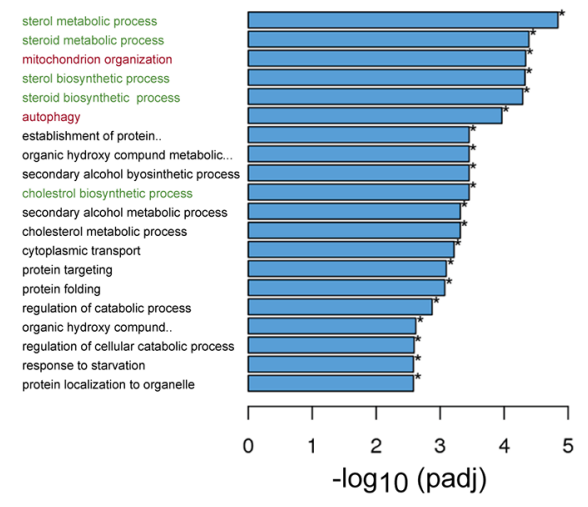

B

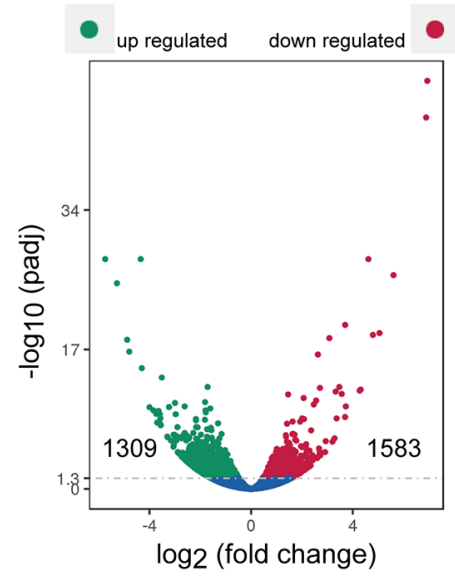

D

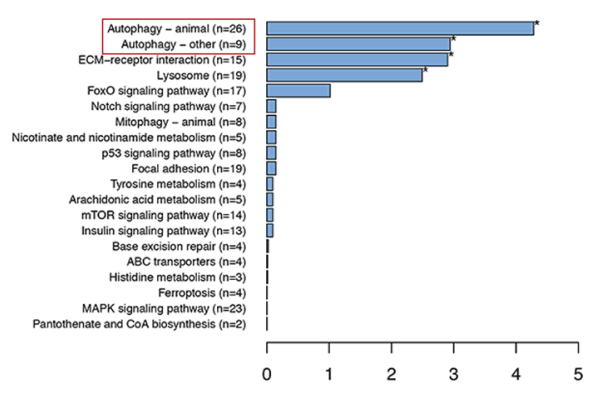

E

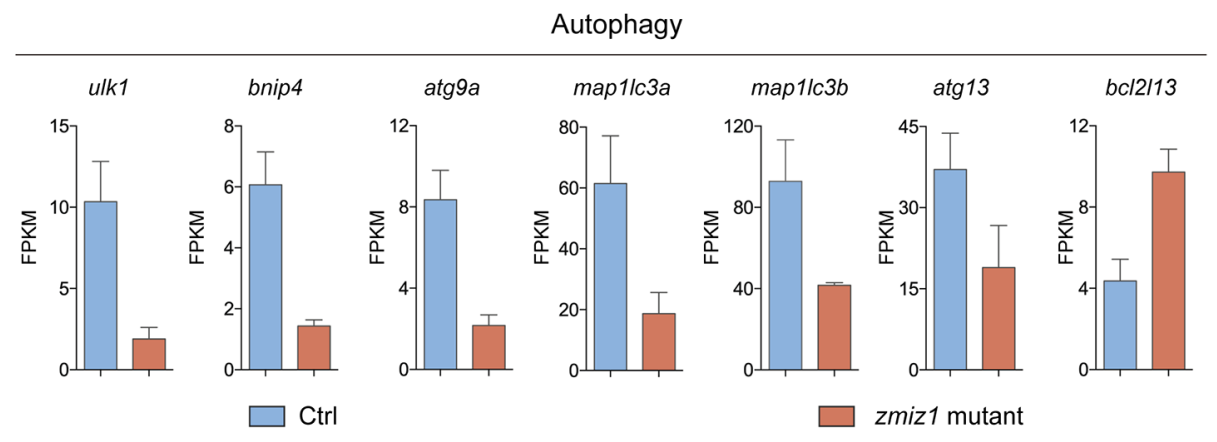




\section{Figure 5.}

Transcriptome analysis of $15 \mathrm{dpf}$ control and zmizla $a^{-/-}$whole embryos. A. Hierarchical Clustering Heatmap of gene expression data determined for four replicate control and three replicate mutant samples. The overall results of FPKM (Fragments Per Kilobase of transcript sequence per Millions of base pairs sequenced) cluster analysis, clustered using the $\log 10$ $(\mathrm{FPKM}+1)$ value. Red denotes genes with high expression levels, and blue denotes genes with low expression levels. The color ranging from red to blue indicates $\log 10(\mathrm{FPKM}+1)$ value from large-to-small. B. Volcano plot. Horizontal axis for the fold change of genes in the control and mutant samples. Vertical axis for statistically significant degree of changes in gene expression levels, the smaller the corrected pvalue, the bigger - $\log 10$ (corrected pvalue), the more significant the difference. The point represents one gene, blue dots indicate no significant difference in genes, red dots indicate upregulated differential expression genes, green dots indicate downregulated differential expression genes. C. GO enrichment bar plot for Biological Process (BP). The top 20 significantly enriched terms in the GO enrichment analysis. D. KEGG enrichment bar plot. The top 20 enriched terms in the KEGG enrichment analysis showing four with significant corrected pvalues. E. Bar charts comparing the normalized average expression levels (FPKM) for autophagy genes $u l k 1 a$, atg9a, bnip4 and atg13 in control and zmizla mutant samples. 


\section{A}

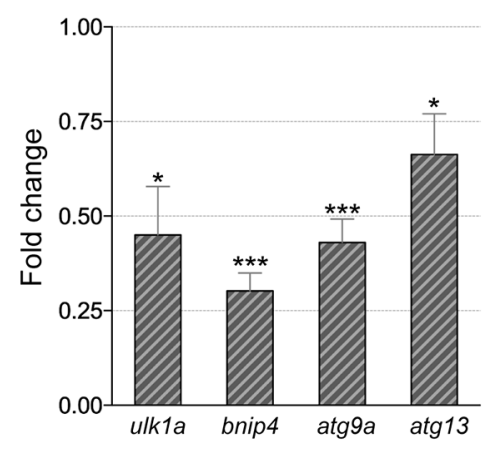

C

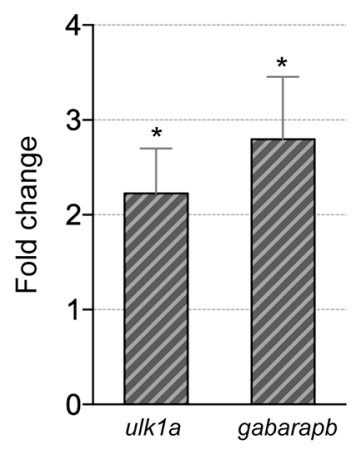

B
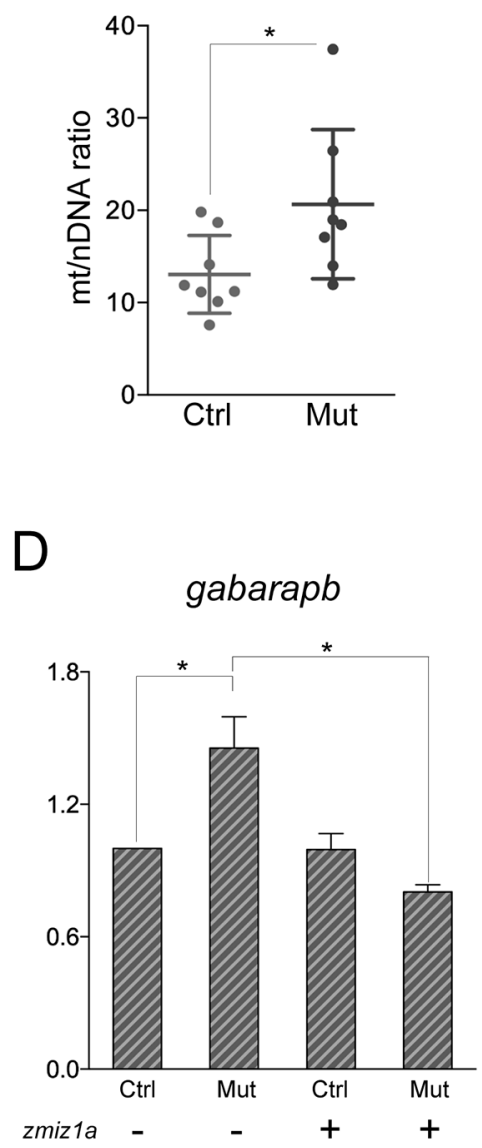

\section{Figure 6.}

Analysis of autophagy gene expression and mitochondrial DNA copy number. A. Quantification by qPCR of autophagy gene expression. 15 dpf embryos were evaluated. For all genes $\mathrm{n} \geq 3 . * \mathrm{P}<0.05, * * * \mathrm{P}<0.001$. B. Quantification of mitochondrial DNA copy number in isolated erythrocytes from control and zmizla mutant $15 \mathrm{dpf}$ larvae. Each point represents the mitochondrial/nuclear DNA ratio determined for the erythrocyte population isolated from one embryo. Mitochondrial and genomic DNA is used for qPCR quantification of $n d l$ and polg1 respectively. Horizontal lines indicate mean values. Data are mean $\pm 1 \mathrm{SD}$ for 8 embryos. P $<0.05$. C. Quantification by qPCR of the expression levels of autophagy genes ulkla, and gabarapb in 48 hpf embryos. For both genes $\mathrm{n} \geq 3$. $\mathrm{P}<0.05$. D. Graph showing a rescue experiment with injected zmizla mRNA. Quantification of gabarapb gene expression shows that the upregulation of gabarapb in the mutant embryos is compensated by the injection of the zmizla mRNA. $\mathrm{n}=4 .{ }^{*} \mathrm{P}<0.05$. 

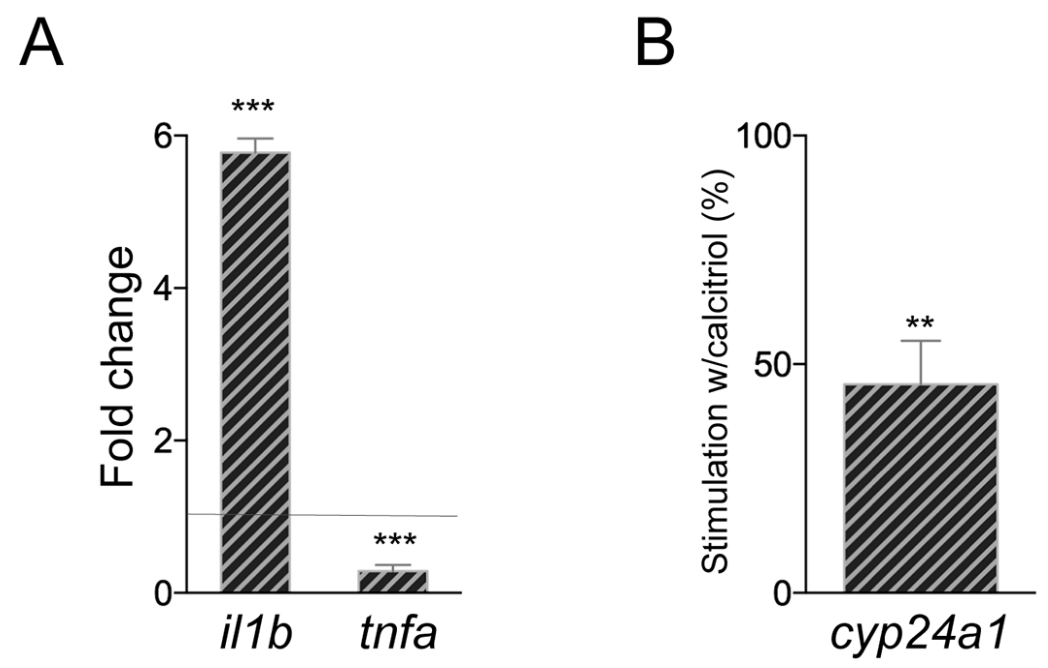

\section{Figure 7.}

Proinflammatory gene expression and response to vitamin D. A. Quantification by qPCR of the expression levels of proinflammatory genes $i l l b$ and thfa in $48 \mathrm{hpf}$ embryos. For both genes $\mathrm{n} \geq 3$. $* * * \mathrm{P}<0.001$. B. Effect of exogenous calcitriol on cyp $24 a \mathrm{l}$ induction in $48 \mathrm{hpf}$ embryos. The graph shows the percentage of stimulation of cyp $24 a 1$ transcription relative to 100 percent assigned to the control embryos, after incubation with calcitriol. Value is the mean $\pm 1 \mathrm{SD} ; \mathrm{n}=4 . \mathrm{P}<0.01$. 


\section{References}

[1] D. Carradice, G.J. Lieschke, Zebrafish in hematology: sushi or science?, Blood 111 (2008) 3331-3342.

[2] E. Dzierzak, N.A. Speck, Of lineage and legacy: the development of mammalian hematopoietic stem cells, Nat Immunol 9 (2008) 129-136.

[3] K. Kulkeaw, D. Sugiyama, Zebrafish erythropoiesis and the utility of fish as models of anemia, Stem Cell Res Ther 3 (2012) 55.

[4] K.J. Carroll, T.E. North, Oceans of opportunity: exploring vertebrate hematopoiesis in zebrafish, Exp Hematol 42 (2014) 684-696.

[5] A.V. Gore, L.M. Pillay, M. Venero Galanternik, B.M. Weinstein, The zebrafish: A fintastic model for hematopoietic development and disease, Wiley Interdiscip Rev Dev Biol 7 (2018) e312.

[6] E.J. Paik, L.I. Zon, Hematopoietic development in the zebrafish, Int J Dev Biol 54 (2010) 1127-1137.

[7] K. Kissa, P. Herbomel, Blood stem cells emerge from aortic endothelium by a novel type of cell transition, Nature 464 (2010) 112-115.

[8] J. Bertrand, N. Chi, B. Santoso, S. Teng, D. Stainier, D. Traver, Haematopoietic stem cells derive directly from aortic endothelium during development, Nature 464 (2010) 108-U120.

[9] E.Y. Lam, C.J. Hall, P.S. Crosier, K.E. Crosier, M.V. Flores, Live imaging of Runx1 expression in the dorsal aorta tracks the emergence of blood progenitors from endothelial cells, Blood 116 (2010) 909-914.

[10] S.K. Nandakumar, J.C. Ulirsch, V.G. Sankaran, Advances in understanding erythropoiesis: evolving perspectives, Br J Haematol 173 (2016) 206-218.

[11] J. Zhang, I. Hamza, Zebrafish as a model system to delineate the role of heme and iron metabolism during erythropoiesis, Mol Genet Metab 128 (2019) 204-212.

[12] L. Gutiérrez, N. Caballero, L. Fernández-Calleja, E. Karkoulia, J. Strouboulis, Regulation of GATA1 levels in erythropoiesis, IUBMB Life 72 (2020) 89-105.

[13] M. Sharma, X. Li, Y. Wang, M. Zarnegar, C.Y. Huang, J.J. Palvimo, B. Lim, Z. Sun, hZimp10 is an androgen receptor co-activator and forms a complex with SUMO-1 at replication foci, EMBO J 22 (2003) 6101-6114.

[14] J. Beliakoff, Z. Sun, Zimp7 and Zimp10, two novel PIAS-like proteins, function as androgen receptor coregulators, Nucl Recept Signal 4 (2006) e017.

[15] R. Carapito, E.L. Ivanova, A. Morlon, L. Meng, A. Molitor, E. Erdmann, B. Kieffer, A. Pichot, L. Naegely, A. Kolmer, N. Paul, A. Hanauer, F. Tran Mau-Them, N. JeanMarçais, S.M. Hiatt, G.M. Cooper, T. Tvrdik, A.M. Muir, C. Dimartino, M. Chopra, J. Amiel, C.T. Gordon, F. Dutreux, A. Garde, C. Thauvin-Robinet, X. Wang, M.S. Leduc, M. Phillips, H.P. Crawford, M.K. Kukolich, D. Hunt, V. Harrison, M. Kharbanda, R. Smigiel, N. Gold, C.Y. Hung, D.H. Viskochil, S.L. Dugan, P. Bayrak-Toydemir, G. JolyHelas, A.M. Guerrot, C. Schluth-Bolard, M. Rio, I.M. Wentzensen, K. McWalter, R.E. Schnur, A.M. Lewis, S.R. Lalani, N. Mensah-Bonsu, J. Céraline, Z. Sun, R. Ploski, C.A. 
Bacino, H.C. Mefford, L. Faivre, O. Bodamer, J. Chelly, B. Isidor, S. Bahram, D.D.D. Study, U.o.W.C.f.M. Genomics, ZMIZ1 Variants Cause a Syndromic Neurodevelopmental Disorder, Am J Hum Genet 106 (2020) 137.

[16] J. Lee, J. Beliakoff, Z. Sun, The novel PIAS-like protein hZimp10 is a transcriptional co-activator of the p53 tumor suppressor, Nucleic Acids Res 35 (2007) 4523-4534.

[17] X. Li, G. Thyssen, J. Beliakoff, Z. Sun, The novel PIAS-like protein hZimp10 enhances Smad transcriptional activity, J Biol Chem 281 (2006) 23748-23756.

[18] N. Pinnell, R. Yan, H.J. Cho, T. Keeley, M.J. Murai, Y. Liu, A.S. Alarcon, J. Qin, Q. Wang, R. Kuick, K.S. Elenitoba-Johnson, I. Maillard, L.C. Samuelson, T. Cierpicki, M.Y. Chiang, The PIAS-like Coactivator Zmiz1 Is a Direct and Selective Cofactor of Notch1 in T Cell Development and Leukemia, Immunity 43 (2015) 870-883.

[19] L.A. Rakowski, D.D. Garagiola, C.M. Li, M. Decker, S. Caruso, M. Jones, R. Kuick, T. Cierpicki, I. Maillard, M.Y. Chiang, Convergence of the ZMIZ1 and NOTCH1 pathways at C-MYC in acute T lymphoblastic leukemias, Cancer Res 73 (2013) 930941.

[20] N. Fewings, P.N. Gatt, F.C. McKay, G.P. Parnell, S.D. Schibeci, J. Edwards, M.A. Basuki, A. Goldinger, M.J. Fabis-Pedrini, A.G. Kermode, C.P. Manrique, J.L. McCauley, D. Nickles, S.E. Baranzini, T. Burke, S. Vucic, G.J. Stewart, D.R. Booth, Data characterizing the ZMIZ1 molecular phenotype of multiple sclerosis, Data Brief 11 (2017) 364-370.

[21] N.L. Fewings, P.N. Gatt, F.C. McKay, G.P. Parnell, S.D. Schibeci, J. Edwards, M.A. Basuki, A. Goldinger, M.J. Fabis-Pedrini, A.G. Kermode, C.P. Manrique, J.L. McCauley, D. Nickles, S.E. Baranzini, T. Burke, S. Vucic, G.J. Stewart, D.R. Booth, The autoimmune risk gene ZMIZ1 is a vitamin D responsive marker of a molecular phenotype of multiple sclerosis, J Autoimmun 78 (2017) 57-69.

[22] G.P. Parnell, S.D. Schibeci, N.L. Fewings, A. Afrasiabi, S.P.L. Law, S. Samaranayake, J.H. Kh'ng, Y.H. Fong, D.A. Brown, C. Liddle, G.J. Stewart, D.R. Booth, The latitudedependent autoimmune disease risk genes ZMIZ1 and IRF8 regulate mononuclear phagocytic cell differentiation in response to vitamin D, Hum Mol Genet 28 (2019) 269-278.

[23] F. Ditrich, S. Blümel, L. Biedermann, N. Fournier, J.B. Rossel, D. Ellinghaus, A. Franke, E.F. Stange, G. Rogler, M. Scharl, S.I.C.S. Group, Genetic risk factors predict disease progression in Crohn's disease patients of the Swiss inflammatory bowel disease cohort, Therap Adv Gastroenterol 13 (2020) 1756284820959252.

[24] S.K. Yang, M. Hong, H. Choi, W. Zhao, Y. Jung, T. Haritunians, B.D. Ye, K.J. Kim, S.H. Park, I. Lee, W.H. Kim, J.H. Cheon, Y.H. Kim, B.I. Jang, H.S. Kim, J.H. Choi, J.S. Koo, J.H. Lee, S.A. Jung, H.D. Shin, D. Kang, H.S. Youn, K.D. Taylor, J.I. Rotter, J. Liu, D.P. McGovern, K. Song, Immunochip analysis identification of 6 additional susceptibility loci for Crohn's disease in Koreans, Inflamm Bowel Dis 21 (2015) 1-7.

[25] D. Ellinghaus, E. Ellinghaus, R.P. Nair, P.E. Stuart, T. Esko, A. Metspalu, S. Debrus, J.V. Raelson, T. Tejasvi, M. Belouchi, S.L. West, J.N. Barker, S. Kõks, K. Kingo, T. Balschun, O. Palmieri, V. Annese, C. Gieger, H.E. Wichmann, M. Kabesch, R.C. Trembath, C.G. Mathew, G.R. Abecasis, S. Weidinger, S. Nikolaus, S. Schreiber, J.T. Elder, M. Weichenthal, M. Nothnagel, A. Franke, Combined analysis of genome- 
wide association studies for Crohn disease and psoriasis identifies seven shared susceptibility loci, Am J Hum Genet 90 (2012) 636-647.

[26] C. Jakobsen, I. Cleynen, P.S. Andersen, S. Vermeire, P. Munkholm, A. Paerregaard, V. Wewer, Genetic susceptibility and genotype-phenotype association in 588 Danish children with inflammatory bowel disease, J Crohns Colitis 8 (2014) 678685.

[27] X. Lan, Y. Chang, X. Zhang, J. Liu, V. Vikash, W. Wang, M. Huang, X. Wang, F. Zhou, L. Chen, $Q$. Zhao, Identification of Two Additional Susceptibility Loci for Inflammatory Bowel Disease in a Chinese Population, Cell Physiol Biochem 41 (2017) 2077-2090.

[28] L.M. Medrano, V. Pascual, A. Bodas, N. López-Palacios, I. Salazar, L. Espino-Paisán, B. González-Pérez, E. Urcelay, J.L. Mendoza, C. Núñez, Expression patterns common and unique to ulcerative colitis and celiac disease, Ann Hum Genet 83 (2019) 86-94.

[29] P.C. Dubois, G. Trynka, L. Franke, K.A. Hunt, J. Romanos, A. Curtotti, A. Zhernakova, G.A. Heap, R. Adány, A. Aromaa, M.T. Bardella, L.H. van den Berg, N.A. Bockett, E.G. de la Concha, B. Dema, R.S. Fehrmann, M. Fernández-Arquero, S. Fiatal, E. Grandone, P.M. Green, H.J. Groen, R. Gwilliam, R.H. Houwen, S.E. Hunt, K. Kaukinen, D. Kelleher, I. Korponay-Szabo, K. Kurppa, P. MacMathuna, M. Mäki, M.C. Mazzilli, O.T. McCann, M.L. Mearin, C.A. Mein, M.M. Mirza, V. Mistry, B. Mora, K.I. Morley, C.J. Mulder, J.A. Murray, C. Núñez, E. Oosterom, R.A. Ophoff, I. Polanco, L. Peltonen, M. Platteel, A. Rybak, V. Salomaa, J.J. Schweizer, M.P. Sperandeo, G.J. Tack, G. Turner, J.H. Veldink, W.H. Verbeek, R.K. Weersma, V.M. Wolters, E. Urcelay, B. Cukrowska, L. Greco, S.L. Neuhausen, R. McManus, D. Barisani, P. Deloukas, J.C. Barrett, P. Saavalainen, C. Wijmenga, D.A. van Heel, Multiple common variants for celiac disease influencing immune gene expression, Nat Genet 42 (2010) 295-302.

[30] Y. Sun, X. Zuo, X. Zheng, F. Zhou, B. Liang, H. Liu, R. Chang, J. Gao, Y. Sheng, H. Cui, W. Wang, A.K. Andiappan, O. Rotzschke, S. Yang, L. Sun, F. Zhang, X. Zhang, Y. Ren, J. Liu, A comprehensive association analysis confirms ZMIZ1 to be a susceptibility gene for vitiligo in Chinese population, J Med Genet 51 (2014) 345-353.

[31] M. Li, Y. Fan, Y. Wang, J. Xu, H. Xu, ZMIZ1 promotes the proliferation and migration of melanocytes in vitiligo, Exp Ther Med 20 (2020) 1371-1378.

[32] Z. Li, J. Chen, Y. Zhao, Y. Wang, J. Xu, J. Ji, J. Shen, W. Zhang, Z. Chen, Q. Sun, L. Mao, S. Cheng, B. Yang, D. Zhang, Y. Xu, D. Liu, Y. Shen, C. Li, Y. Shi, Common variants in ZMIZ1 and near NGF confer risk for primary dysmenorrhoea, Nat Commun 8 (2017) 14900.

[33] M.K. Andersen, M. Sterner, T. Forsén, A. Käräjämäki, O. Rolandsson, C. Forsblom, P.H. Groop, K. Lahti, P.M. Nilsson, L. Groop, T. Tuomi, Type 2 diabetes susceptibility gene variants predispose to adult-onset autoimmune diabetes, Diabetologia 57 (2014) 1859-1868.

[34] M.N. Harder, R. Ribel-Madsen, J.M. Justesen, T. Spars $\varnothing$, E.A. Andersson, N. Grarup, T. Jørgensen, A. Linneberg, T. Hansen, O. Pedersen, Type 2 diabetes risk alleles near BCAR1 and in ANK1 associate with decreased $\beta$-cell function whereas risk 
alleles near ANKRD55 and GRB14 associate with decreased insulin sensitivity in the Danish Inter99 cohort, J Clin Endocrinol Metab 98 (2013) E801-806.

[35] K.M. O'Brien, S.R. Cole, C. Poole, J.T. Bensen, A.H. Herring, L.S. Engel, R.C. Millikan, Replication of breast cancer susceptibility loci in whites and African Americans using a Bayesian approach, Am J Epidemiol 179 (2014) 382-394.

[36] A.C. Antoniou, K.B. Kuchenbaecker, P. Soucy, J. Beesley, X. Chen, L. McGuffog, A. Lee, D. Barrowdale, S. Healey, O.M. Sinilnikova, M.A. Caligo, N. Loman, K. Harbst, A. Lindblom, B. Arver, R. Rosenquist, P. Karlsson, K. Nathanson, S. Domchek, T. Rebbeck, A. Jakubowska, J. Lubinski, K. Jaworska, K. Durda, E. ZłowowckaPerłowska, A. Osorio, M. Durán, R. Andrés, J. Benítez, U. Hamann, F.B. Hogervorst, T.A. van Os, S. Verhoef, H.E. Meijers-Heijboer, J. Wijnen, E.B. Gómez Garcia, M.J. Ligtenberg, M. Kriege, J.M. Collée, M.G. Ausems, J.C. Oosterwijk, S. Peock, D. Frost, S.D. Ellis, R. Platte, E. Fineberg, D.G. Evans, F. Lalloo, C. Jacobs, R. Eeles, J. Adlard, R. Davidson, T. Cole, J. Cook, J. Paterson, F. Douglas, C. Brewer, S. Hodgson, P.J. Morrison, L. Walker, M.T. Rogers, A. Donaldson, H. Dorkins, A.K. Godwin, B. Bove, D. Stoppa-Lyonnet, C. Houdayer, B. Buecher, A. de Pauw, S. Mazoyer, A. Calender, M. Léoné, B. Bressac-de Paillerets, O. Caron, H. Sobol, M. Frenay, F. Prieur, S.U. Ferrer, I. Mortemousque, S. Buys, M. Daly, A. Miron, M.U. Terry, J.L. Hopper, E.M. John, M. Southey, D. Goldgar, C.F. Singer, A. Fink-Retter, M.K. Tea, D.U. Kaulich, T.V. Hansen, F.C. Nielsen, R.B. Barkardottir, M. Gaudet, T. Kirchhoff, V. Joseph, A. Dutra-Clarke, K. Offit, M. Piedmonte, J. Kirk, D. Cohn, J. Hurteau, J. Byron, J. Fiorica, A.E. Toland, M. Montagna, C. Oliani, E. Imyanitov, C. Isaacs, L. Tihomirova, I. Blanco, C. Lazaro, A. Teulé, J.D. Valle, S.A. Gayther, K. Odunsi, J. Gross, B.Y. Karlan, E. Olah, S.H. Teo, P.A. Ganz, M.S. Beattie, C.M. Dorfling, E.U. van Rensburg, O. Diez, A. Kwong, R.K. Schmutzler, B. Wappenschmidt, C. Engel, A. Meindl, N. Ditsch, N. Arnold, S. Heidemann, D. Niederacher, S. Preisler-Adams, D. Gadzicki, R. VaronMateeva, H. Deissler, A. Gehrig, C. Sutter, K. Kast, B. Fiebig, D. Schäfer, T. Caldes, M. de la Hoya, H. Nevanlinna, T.A. Muranen, B. Lespérance, A.B. Spurdle, S.L. Neuhausen, Y.C. Ding, X. Wang, Z. Fredericksen, V.S. Pankratz, N.M. Lindor, P. Peterlongo, S. Manoukian, B. Peissel, D. Zaffaroni, B. Bonanni, L. Bernard, R. Dolcetti, L. Papi, L. Ottini, P. Radice, M.H. Greene, J.T. Loud, I.L. Andrulis, H. Ozcelik, A.U. Mulligan, G. Glendon, M. Thomassen, A.M. Gerdes, U.B. Jensen, A.B. Skytte, T.A. Kruse, G. Chenevix-Trench, F.J. Couch, J. Simard, D.F. Easton, S.W.E.-B. CIMBA, HEBON, EMBRACE, G.C. Study, k. Investigators, Common variants at 12p11, 12q24, 9p21, 9q31.2 and in ZNF365 are associated with breast cancer risk for BRCA1 and/or BRCA2 mutation carriers, Breast Cancer Res 14 (2012) R33.

[37] B. Zhang, W.H. Jia, K. Matsuda, S.S. Kweon, K. Matsuo, Y.B. Xiang, A. Shin, S.H. Jee, D.H. Kim, Q. Cai, J. Long, J. Shi, W. Wen, G. Yang, Y. Zhang, C. Li, B. Li, Y. Guo, Z. Ren, B.T. Ji, Z.Z. Pan, A. Takahashi, M.H. Shin, F. Matsuda, Y.T. Gao, J.H. Oh, S. Kim, Y.O. Ahn, A.T. Chan, J. Chang-Claude, M.L. Slattery, S.B. Gruber, F.R. Schumacher, S.L. Stenzel, G. Casey, H.R. Kim, J.Y. Jeong, J.W. Park, H.L. Li, S. Hosono, S.H. Cho, M. Kubo, X.O. Shu, Y.X. Zeng, W. Zheng, G.a.E.o.C.C.C. (GECCO), C.T.C. Study, C.C.F.R. (CCFR), Large-scale genetic study in East Asians identifies six new loci associated with colorectal cancer risk, Nat Genet 46 (2014) 533-542. 
[38] N. Song, K. Kim, A. Shin, J.W. Park, H.J. Chang, J. Shi, Q. Cai, D.Y. Kim, W. Zheng, J.H. Oh, Colorectal cancer susceptibility loci and influence on survival, Genes Chromosomes Cancer 57 (2018) 630-637.

[39] L.M. Rogers, J.D. Riordan, B.L. Swick, D.K. Meyerholz, A.J. Dupuy, Ectopic expression of Zmiz1 induces cutaneous squamous cell malignancies in a mouse model of cancer, J Invest Dermatol 133 (2013) 1863-1869.

[40] J. Beliakoff, J. Lee, H. Ueno, A. Aiyer, I.L. Weissman, G.S. Barsh, R.D. Cardiff, Z. Sun, The PIAS-like protein Zimp10 is essential for embryonic viability and proper vascular development, Mol Cell Biol 28 (2008) 282-292.

[41] M. Westerfield, The zebrafish book : a guide for the laboratory use of zebrafish Danio (Brachydanio) rerio.

[42] C.B. Kimmel, W.W. Ballard, S.R. Kimmel, B. Ullmann, T.F. Schilling, Stages of embryonic development of the zebrafish, Dev Dyn 203 (1995) 253-310.

[43] C. Thisse, B. Thisse, High-resolution in situ hybridization to whole-mount zebrafish embryos, Nat Protoc 3 (2008) 59-69.

[44] H.W. Detrich, M.W. Kieran, F.Y. Chan, L.M. Barone, K. Yee, J.A. Rundstadler, S. Pratt, D. Ransom, L.I. Zon, Intraembryonic hematopoietic cell migration during vertebrate development, Proc Natl Acad Sci U S A 92 (1995) 10713-10717.

[45] M.V. Flores, E.Y. Lam, P. Crosier, K. Crosier, A hierarchy of Runx transcription factors modulate the onset of chondrogenesis in craniofacial endochondral bones in zebrafish, Dev Dyn 235 (2006) 3166-3176.

[46] C.E. Willett, J.J. Cherry, L.A. Steiner, Characterization and expression of the recombination activating genes (rag1 and rag2) of zebrafish, Immunogenetics 45 (1997) 394-404.

[47] L. Yin, L.E. Jao, W. Chen, Generation of Targeted Mutations in Zebrafish Using the CRISPR/Cas System, Methods Mol Biol 1332 (2015) 205-217.

[48] R.D. Cardiff, C.H. Miller, R.J. Munn, Manual hematoxylin and eosin staining of mouse tissue sections, Cold Spring Harb Protoc 2014 (2014) 655-658.

[49] N.N. Paffett-Lugassy, L.I. Zon, Analysis of hematopoietic development in the zebrafish, Methods Mol Med 105 (2005) 171-198.

[50] A. Oshlack, M.D. Robinson, M.D. Young, From RNA-seq reads to differential expression results, Genome Biol 11 (2010) 220.

[51] M.D. Young, M.J. Wakefield, G.K. Smyth, A. Oshlack, Gene ontology analysis for RNA-seq: accounting for selection bias, Genome Biol 11 (2010) R14.

[52] M. Kanehisa, S. Goto, KEGG: kyoto encyclopedia of genes and genomes, Nucleic Acids Res 28 (2000) 27-30.

[53] R. Moreno-Ayala, D. Schnabel, E. Salas-Vidal, H. Lomelí, PIAS-like protein Zimp7 is required for the restriction of the zebrafish organizer and mesoderm development, Dev Biol 403 (2015) 89-100.

[54] H. Rodriguez-Magadán, E. Merino, D. Schnabel, L. Ramírez, H. Lomelí, Spatial and temporal expression of Zimp7 and Zimp10 PIAS-like proteins in the developing mouse embryo, Gene Expr Patterns 8 (2008) 206-213.

[55] V.M. Betin, B.K. Singleton, S.F. Parsons, D.J. Anstee, J.D. Lane, Autophagy facilitates organelle clearance during differentiation of human erythroblasts: evidence for a 
role for ATG4 paralogs during autophagosome maturation, Autophagy 9 (2013) 881-893.

[56] M. Mortensen, D.J. Ferguson, A.K. Simon, Mitochondrial clearance by autophagy in developing erythrocytes: clearly important, but just how much so?, Cell Cycle 9 (2010) 1901-1906.

[57] M. Kundu, T. Lindsten, C.Y. Yang, J. Wu, F. Zhao, J. Zhang, M.A. Selak, P.A. Ney, C.B. Thompson, Ulk1 plays a critical role in the autophagic clearance of mitochondria and ribosomes during reticulocyte maturation, Blood 112 (2008) 1493-1502.

[58] G. Davuluri, P. Song, Z. Liu, D. Wald, T.F. Sakaguchi, M.R. Green, L. Devireddy, Inactivation of 3-hydroxybutyrate dehydrogenase 2 delays zebrafish erythroid maturation by conferring premature mitophagy, Proc Natl Acad Sci U S A 113 (2016) E1460-1469.

[59] L. Artuso, A. Romano, T. Verri, A. Domenichini, F. Argenton, F.M. Santorelli, V. Petruzzella, Mitochondrial DNA metabolism in early development of zebrafish (Danio rerio), Biochim Biophys Acta 1817 (2012) 1002-1011.

[60] D. Sharma, T.D. Kanneganti, The cell biology of inflammasomes: Mechanisms of inflammasome activation and regulation, J Cell Biol 213 (2016) 617-629.

[61] Y. Xu, J. Shen, Z. Ran, Emerging views of mitophagy in immunity and autoimmune diseases, Autophagy 16 (2020) 3-17.

[62] A. Hanel, H.R. Malmberg, C. Carlberg, Genome-wide effects of chromatin on vitamin D signaling, J Mol Endocrinol 64 (2020) R45-R56.

[63] Y.A. Kang, R. Sanalkumar, H. O'Geen, A.K. Linnemann, C.J. Chang, E.E. Bouhassira, P.J. Farnham, S. Keles, E.H. Bresnick, Autophagy driven by a master regulator of hematopoiesis, Mol Cell Biol 32 (2012) 226-239.

[64] S. Honda, S. Arakawa, Y. Nishida, H. Yamaguchi, E. Ishii, S. Shimizu, Ulk1-mediated Atg5-independent macroautophagy mediates elimination of mitochondria from embryonic reticulocytes, Nat Commun 5 (2014) 4004.

[65] S. Shimizu, Alternative autophagy plays a central role in mitochondria elimination from reticulocytes, Rinsho Ketsueki 58 (2017) 649-653.

[66] Q. Wang, R. Yan, N. Pinnell, A.C. McCarter, Y. Oh, Y. Liu, C. Sha, N.F. Garber, Y. Chen, Q. Wu, C.J. Ku, I. Tran, A. Serna Alarcon, R. Kuick, J.D. Engel, I. Maillard, T. Cierpicki, M.Y. Chiang, Stage-specific roles for Zmiz1 in Notch-dependent steps of early T-cell development, Blood 132 (2018) 1279-1292.

[67] E. Wienholds, S. Schulte-Merker, B. Walderich, R.H. Plasterk, Target-selected inactivation of the zebrafish rag1 gene, Science 297 (2002) 99-102.

[68] S.D. Tyrkalska, A.B. Pérez-Oliva, L. Rodríguez-Ruiz, F.J. Martínez-Morcillo, F. Alcaraz-Pérez, F.J. Martínez-Navarro, C. Lachaud, N. Ahmed, T. Schroeder, I. PardoSánchez, S. Candel, A. López-Muñoz, A. Choudhuri, M.P. Rossmann, L.I. Zon, M.L. Cayuela, D. García-Moreno, V. Mulero, Inflammasome Regulates Hematopoiesis through Cleavage of the Master Erythroid Transcription Factor GATA1, Immunity 51 (2019) 50-63.e55. 